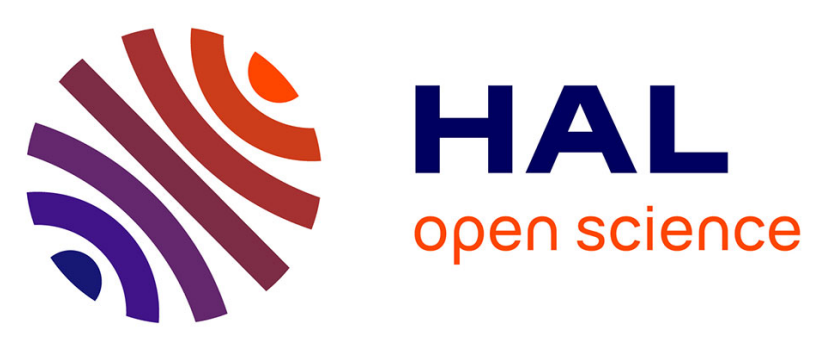

\title{
Characteristics and outcome according to underlying disease in non-AIDS patients with acute respiratory failure due to Pneumocystis pneumonia
}

\author{
Gaston Burghi, Lucie Biard, Antoine Roux, Sandrine Valade, Florence
}

Robert-Gangneux, Samia Hamane, Danièle Maubon, Anne Debourgogne,

Solene Le Gal, Frédéric Dalle, et al.

\section{To cite this version:}

Gaston Burghi, Lucie Biard, Antoine Roux, Sandrine Valade, Florence Robert-Gangneux, et al.. Characteristics and outcome according to underlying disease in non-AIDS patients with acute respiratory failure due to Pneumocystis pneumonia. European Journal of Clinical Microbiology and Infectious Diseases, 2021, 40 (6), pp.1191-1198. 10.1007/s10096-020-04118-w . hal-03131261

\author{
HAL Id: hal-03131261 \\ https://hal.science/hal-03131261
}

Submitted on 23 Mar 2021

HAL is a multi-disciplinary open access archive for the deposit and dissemination of scientific research documents, whether they are published or not. The documents may come from teaching and research institutions in France or abroad, or from public or private research centers.
L'archive ouverte pluridisciplinaire HAL, est destinée au dépôt et à la diffusion de documents scientifiques de niveau recherche, publiés ou non, émanant des établissements d'enseignement et de recherche français ou étrangers, des laboratoires publics ou privés. 
1 Characteristics and outcome according to underlying disease in non-AIDS patients with acute respiratory failure due to Pneumocystis pneumonia

Gaston Burghi ${ }^{1}$, Lucie Biard ${ }^{2}$, Antoine Roux ${ }^{3}$, Sandrine Valade ${ }^{1}$, Florence Robert-Gangneux ${ }^{4}$, Samia Hamane $^{1}$, Daniéle Maubon ${ }^{5}$, Anne Debourgogne ${ }^{6}$, Soléne Le Gal ${ }^{7}$, Fréderic Dalle ${ }^{8}$, Marion Leterrier ${ }^{9}$, Dominique Toubas $^{10}$, Christelle Pomares ${ }^{11}$, Anne Pauline Bellanger ${ }^{12}$, Julie Bonhomme ${ }^{13}$, Antoine Berry $^{14}$, Xavier Iriart ${ }^{14}$, Isabelle Durand-Joly ${ }^{15}$, Denis Magne ${ }^{16}$, Denis Pons ${ }^{17}$, Christophe Hennequin ${ }^{18}$, Eric Maury ${ }^{16}$, Elie Azoulay ${ }^{1}$, Virginie Lemiale ${ }^{1}$

${ }^{1}$ AP-HP, Hôpital Saint-Louis, Medical ICU, Paris, France; University of Paris, UFR de Médecine ${ }^{2}$ AP-HP, Hôpital Saint-Louis, SBIM, Paris, France; University of Paris, UFR de Médecine

${ }^{3}$ Centre Medico-Chirurgical FOCH, Suresnes

4 Univ Rennes, CHU Rennes, Inserm, EHESP, Irset (Institut de Recherche en Santé Environnement Travail), UMR_S 1085, 35000, Rennes, France

${ }^{5} \mathrm{CHU}$ de Grenoble, Grenoble, France

6 Université de Lorraine, CHRU-Nancy, laboratoire de Microbiologie, F-54000 Nancy, France

${ }^{7}$ Centre Hospitalier Régional et Universitaire de Brest, Brest, France

${ }^{8}$ Centre Hospitalier Universitaire de Dijon, Laboratoire de Parasitologie-Mycologie, Dijon, France; UMR PAM, Agrosup, Université de Bourgogne-Franche Comté, Dijon, France.

${ }^{9} \mathrm{CHU}$ de Nantes, Nantes, France

${ }^{10} \mathrm{CHU}$ de Reims, Reims, France

${ }^{11}$ Service de Parasitologie - Mycologie CHU Nice, UCA, INSERM 1065 C3M, France.

${ }_{12} \mathrm{CHU}$ Jean Minjoz, Besançon, France

${ }^{13} \mathrm{CHU}$ Côte de Nacre; Normandie University, UNICAEN, Caen, France ${ }^{14} \mathrm{CHU}$ de Toulouse, Toulouse, France; Centre de Physiopathologie Toulouse Purpan (CPTP), Université de Toulouse, INSERM, CNRS, UPS, Toulouse, France.

${ }^{15} \mathrm{CHU}$ de Lille, Lille France and $\mathrm{CH}$ de Dunkerque, Dunkerque , France

${ }^{16}$ AP-HP, Hôpital St Antoine, Université de Paris

${ }^{17} \mathrm{CHU}$ Gabriel Montpied, Clermont-Ferrand, France

18 Sorbonne Université, Inserm, Centre de Recherche Saint-Antoine, CRSA, AP-HP, Hôpital Saint-

Antoine, Service de Parasitologie-Mycologie, F-75012 Paris, France

Running title: Pneumocystis pneumonia in non-AIDS patients

Word count: 2159 (abstract 196)

Keywords: Pneumocystis, ICU, immunosuppression, outcome

The initial cohort was supported by a grant from the French ministry of health.

Corresponding author

Dr. Virginie Lemiale

AP-HP, Hôpital Saint-Louis, Medical ICU, Paris, France; University Paris-7 Paris-Diderot, UFR de Médecine, 75010 Paris, France 
44 Purpose : In the non-AIDS group, several underlying conditions and immune defects could lead to different PCP presentations. This study compared PCP presentation and outcome according to the underlying disease.

Methods : Secondary analysis of a previous published prospective observational study including 544 PCP patients. Only non-AIDS patients were included. Underlying disease was defined as chronic lymphocytic leukemia (CLL), organ transplantation, solid cancer, allogenic hematopoietic stem cell transplant (AHSCT), other hematological diseases, and immunosuppressive treatment. Clinical characteristics and outcome were compared between groups. Multiple correspondent analyses compared clinical characteristics at diagnosis. Day 30 (Day 30) mortality was analyzed.

Results: Three hundred and twenty-one patients were included in the study. The underlying diseases were hematological malignancy $(n=75)$, (AHSCT) $(n=14)$, CLL ( $n=19)$, solid organ transplant $(n=94)$, solid tumor $(n=39)$, and immunosuppressive treatment $(n=57)$. Compared with other underlying diseases, PCP related to CLL was closer to PCP related to AIDS presentation (long duration of symptoms before diagnosis, high level of dyspnea, and low oxygen saturation at diagnosis). Day 30 mortality was associated with underlying disease, oxygen flow, and shock at ICU admission. Conclusion: PCP presentations may vary according to the underlying reason for immunosuppression. Response to treatment and adjuvant steroid therapy should be analyzed regarding this result. 
Introduction

68 Pneumocystis jirovecii pneumonia (PCP) remains a life-threatening, opportunistic disease related to $\mathrm{T}$ cell suppression, macrophage defect, or other immunodeficiencies. New treatments and higher life expectancies in various oncologic or immune disease illustrate that PCP among non-AIDS patients is steadily increasing [1-6].

Several studies thus far have demonstrated significant differences between AIDS and nonAIDS patients in clinical pictures, physiopathology, and mortality related to PCP. In fact, non-AIDS patients experienced a shorter length of symptoms, a higher inflammation in the lungs, and a significantly higher severity and mortality despite a lower pulmonary burden of Pneumocystis [6-8].

However, immunosuppressive conditions leading to PCP onset remain different inside the subgroup of non-AIDS patients. Immune defects for solid organ transplant recipients may be different from those in chronic lymphoid leukemia (CLL) patients or solid tumor patients [9-11]. The clinical presentation and response to treatment may vary between all those underlying diseases, but those differences are not well established in the literature.

82 Indeed, comparing patients inside the non-AIDS group may be of importance.

83 The aim of this study was to identify different clinical profiles and mortality-related factors among the different non-AIDS groups at risk for PCP. 


\section{Materials and methods}

The study was a secondary analysis of an observational study. The study has already been described [6]. Briefly, between January 1, 2007, and December 31, 2010, all consecutive patients (AIDS infected or non-AIDS infected patients) with confirmed Pneumocystis pneumonia were included in the study. The study was conducted in accordance with French law for observational studies on retrospective data which did not require patient consent for this analysis. Confirmed Pneumocystis pneumonia was defined as having a positive result for Pneumocystis jirovecii by Gomori-Grocott or toluidine blue stain or positive immunofluorescence test results for a broncho-alveolar lavage (BAL) fluid or induced sputum specimen. Patients for whom only PCR results were positive were not included in the study.

All clinical, biological, and imaging data were prospectively reviewed based on patients hospitalization records. Clinical characteristics at admission included respiratory symptoms and extra-respiratory organ failure.

Diagnosis criteria were assessed, and outcome during ICU stay was recorded.

In this secondary study, only non-AIDS patients were analyzed. Underlying diseases were described as chronic lymphoid leukemia (CLL) diagnosis with or without treatment, AHSCT whatever the length from transplantation, other acute hematological malignancies, active solid tumor when patients had been treated within the past 5 years with chemotherapy, solid organ transplantation, immunosuppressive treatment for immune disease, or other reasons. Because of the high prevalence of PCP during CLL and the physiopathology

111 assumed close to the one of PCP related to AIDS, patients with CLL was firstly described 112 separately [12,13]. For CLL patients, high prevalence of PCP was usually associated T 113 cell depletion related to fludarabine treatment [9] In the further analysis, all patients with 
114 hematological malignancies were analyzed in the same group. In case of several

115 underlying disease, hematological disease was first considered (for example, if patient had

116 hematological disease after solid organ transplantation (SOT), he was considered as

117 hematological patient), then the most recent underlying disease (for example if patient with

118 SOT had a recent increase of immunosuppressive treatment, he was classified as drug

119 related immune suppression).

120 Characteristics at diagnosis and outcome were analyzed. Prophylaxis was defined as an 121 antifungal therapy before PCP onset (sulfamethoxazole/trimethoprim or atovaquone or

122 pentamidine). Shock was defined with the need of vasopressors. Only day 30 mortality 123 was analyzed.

125 Statistical Analysis

126 Data from clinical or biological presentation and outcome were described according to

127 underlying disease. Quantitative variables are presented as median (interquartile range)

128 and were compared between disease groups using Kruskal-Wallis tests; categorical

129 variables are presented as count (percent) and were compared between groups using $\mathrm{X}^{2}$ 130 tests.

131 Multiple correspondence analysis (MCA) was performed to identify profiles of clinical

132 presentation in non-AIDS Pneumocystis patients, possibly related to the underlying 133 diseases. For the MCA, missing data were handled by imputation using a correspondence 134 analysis procedure, with the missMDA package on $\mathrm{R}$ statistical platform. We report figures 135 illustrating the first two components describing variability in observations based on clinical 136 presentation signs. In figure 1, underlying diseases have been added on the plot to 137 illustrate the link between clinical variables and underlying disease. Figure 2 represents 138 the corresponding individuals factor map according to the underlying disease. 
139 Factors associated with Day 30 mortality were evaluated with univariate analysis using a

140 logistic regression model estimating odds ratios and their $95 \%$ confidence intervals. in the 141 sample with available follow-up data $(n=280)$. Variables that were significant at the $5 \%$

142 level in univariate analysis were candidates for multivariate analysis. A multivariate model

143 was selected using a backward stepwise selection procedure based on $p$-values

144 (threshold $=0.05$ ). The main analysis was performed using multiple imputations by

145 chained equations to handle missing data (50 imputations with 20 iterations). Estimates for

146 the effect of variables on mortality from imputed data were computed using Rubin's rules.

147 A sensitivity analysis was performed using a complete-cases approach, yielding consistent

148 results

149 A sensitivityanalysis was performed using a completo-cases approach, yielding-consistent

150 results.

151 All tests were two-sided, and a p-value lower than 0.05 was considered as indicating a

152 significant association. Analyses were performed on the $\mathrm{R}$ statistical platform, version

153 3.2.2 with the FactoMineR, missMDA, and mice packages. 


\section{Results}

158 During the study period, 321 non-AIDS immunosuppressed patients were included in the 159 study. Median age was 59 [IQR 46-68] years, and 193 (62\%) patients were male.

160 Underlying immunosuppression was related to hematological malignancy ( $n=75,23 \%$ ),

161 chronic lymphoid leukemia $(n=19 ; 6 \%)$, AHSCT $(n=14 ; 4 \%)$, solid tumor $(n=39 ; 12 \%)$,

162 SOT ( $\mathrm{n}=94 ; 29 \%$ ) or immunosuppressive treatment for other reasons $(\mathrm{n}=57 ; 18 \%$ ), and

163 other immunosuppressive reasons $(n=23 ; 7 \%)$. Hematological diseases were mostly non

164 Hodgkin or Hodgkin disease ( $n=46$, including 6 autologous HSCT), multiple myeloma

$165(n=10)$ or acute myeloid leukemia $(n=9)$. Solid organ transplantations were mostly kidney

166 transplantation (77/94). Immunosuppressive treatment for underlying disease as

167 connective tissue disease or systemic vasculitis was steroid $(n=27)$, chemotherapy $+/-$

168 steroids $(n=21)$, anti CD20 $+/$ - steroids $(n=4)$, other $(n=5)$. Other immunosuppressive conditions were pulmonary or cutaneous underlying diseases resulting in intermittent steroids treatment $(n=14)$, underlying connective tissue disease without treatment $(n=6)$,

171 unknown reason of immunosuppression in the database $(n=3)$. At the time of diagnosis,

172 most of the patients did not receive anti-Pneumocystis prophylaxis or had recently

173 withdrawn prophylaxis $(n=266 ; 83 \%)$.

174 The delay between respiratory symptoms and diagnosis was 5 [1-15] days, and below 7 175 days for $135(42 \%)$ patients.

176 Clinical presentations included fever over $38^{\circ} \mathrm{C}(\mathrm{n}=181 ; 83 \%)$, cough $(\mathrm{n}=109 ; 54 \%)$, and 177 dyspnea $(n=151 ; 73 \%)$. Oxygen flow required at diagnosis was 0 [IQR $0-6] \mathrm{I} / \mathrm{min}$. Half of 178 the patients were admitted to the ICU $(n=134 ; 50 \%)$. Noninvasive mechanical ventilation was required for 50 (15.6\%) patients, among whom 46 (92\%) needed secondary invasive 
180 mechanical ventilation (iMV). One-third of the patients $(n=98 ; 30.5 \%)$ needed iMV. Shock 181 occurred at diagnosis in $22(6.8 \%)$ patients.

182 Pulmonary co-infections were frequent with bacteria $(n=48 ; 17 \%)$ or virus $(n=26 ; 9 \%)$.

183 Viral coinfection included $16 \mathrm{CMV}$ infections and 8 herpes simplex virus infections.

184 Bacterial co-infections were mostly related to Pseudomonas $(\mathrm{n}=9)$, Streptococcus 185 pneumonia $(\mathrm{n}=9)$, Escherichia Coli $(\mathrm{n}=4)$, Staphylococcus or enterococcus $(\mathrm{n}=12)$.

186 The lung CT scans of $165(51.4 \%)$ patients were analyzed. Ground-glass opacity was the

187 most frequent lesion $(n=110 ; 67 \%)$ but was associated with alveolar lesion in $36(22 \%)$

188 patients. For 3 patients $(2 \%)$, the lung CT scans was normal.

189 The delay from hospital admission to treatment was 2 [0-6] days. Adjuvant steroid therapy 190 was prescribed in $106(43 \%)$ patients.

191 Table 1 described the clinical presentation and outcome according to the underlying 192 disease. In this table, some characteristics must be highlighted. First, the duration of 193 symptoms before diagnosis was longer for CLL and AHSCT (respectively 15 [10-26] and 19426 [12-30] days), close to the duration in AIDS patients. Prophylaxis guidelines were 195 different according to the underlying disease, and PCP occurred mostly during prophylaxis 196 vacancy. Steroid before PCP onset was differentially prescribed depending on the 197 underlying disease $(p<0.001)$; the highest frequency of steroid prescription was observed 198 in patients with solid organ transplant or immunosuppressive treatment consistent with the 199 usual treatment regimen for those underlying diseases. Although symptoms were similar 200 for all underlying diseases, cough prevalence was different according to the underlying 201 disease $(p<0.001)$; it was mostly observed in hematological diseases, including CLL and 202 AHSCT patients.

203 Age at diagnosis was different, reflecting the underlying age onset for each disease group. 
204 Multiple correspondence analyses (Figs. 1 and 2) highlight those clinical differences 205 according to the underlying disease. Overall, clinical presentation variables could be 206 summarized in two main components explaining respectively $25.7 \%$ and $22.6 \%$ of 207 observations variability. The presence of a coinfection was the main characteristic 208 discriminating 2 clinical profiles.

209 Day 30 mortality was 23\% $(n=64 / 280)$. Table 2 described the univariate analysis of 210 factors associated with Day 30 mortality. Table 3 described the multivariate analysis of 211 factors associated with Day 30 mortality. Higher oxygen flow at admission $(\mathrm{OR}=1.16$ per $2121 \mathrm{~L} / \mathrm{min}$ increment [1.08-1.24], $\mathrm{p}<0.001)$ and shock at ICU admission $(\mathrm{OR}=7.67$ [2.63213 22.37], $p=0.0002)$ were associated with higher mortality. On the contrary, solid organ 214 transplant $(O R=0.19[0.07-0.53], p=0.001)$ was associated with lower mortality rate 215 compared to patients with immune diseases or solid tumors. The sensitivity analysis on the 216 complete-case dataset was consistent with these results and is reported in table 1 suppl. 


\section{Discussion}

219 This study is the first to compare several immunosuppressive conditions for PCP onset.

220 Although the study was mostly an exploratory analysis several points should be

221 highlighted. The study included a high number of patients with PCP. Although prevalence

222 of PCP outside the group of AIDS patients, has been increasing, the number of cases has

223 remained low, and this study included all the patients in 17 French hospitals within a three-

224 year period $[6,14,15]$. We found that several immune conditions lead to variable clinical

225 presentations.

226 First, PCP occurred in patients without prophylaxis, and the incidence of prophylaxis

227 varied inside the non-AIDS group. Although prophylaxis remains recommended in CLL

228 patients with treatment or in solid organ transplant patients during more than 6 months

229 (depending on the organ) after transplant [20], there are no guidelines regarding the

230 patients with solid tumor or receiving immunosuppressive treatment. However, this study

231 confirmed that prophylactic treatment should be discussed for patients with

232 immunosuppressive treatment, particularly for those who need steroid boli for rejection

233 treatment in solid organ transplant or graft-vs.-host disease [4]. Also, prophylaxis may be

234 discussed for some kinds of solid tumors for patients who receive steroids [3].

235 Second, clinical presentation seems different between underlying diseases. Presentation

236 of PCP related to CLL or AHSCT were closer to that occurring in AIDS patients than other

237 underlying diseases with a long duration of symptoms before diagnosis, high level of

238 dyspnea, and low oxygen saturation at diagnosis. Furthermore, physiopathology of

239 immunosuppression is different for those diseases. The use of fludarabine during the

240 course of treatment for CLL or before AHSCT leads to a profound T cell depletion as in

241 severe AIDS infection [9]. T cells are known to be involved in Pneumocystis clearance and

242 also the CD4/CD8 ratio could regulate lung inflammation. Therefore, the duration of 
243 symptoms for LLC and AHSCT could be related to T cell depletion after fludarabine.

244 Secondarily after fludarabine treatment, T cell recovery has been associated with a shift

245 toward Th1 cytokine secretion and could be associated with higher lung inflammation [9].

246 On the contrary, immunosuppressive treatment for immune disease or solid organ

247 transplant, mostly steroid therapy, have been associated with altered macrophage

248 function. Macrophages are highly involved in Pneumocystis pathogenicity. Indeed, a

249 recent study demonstrated the double role of macrophages in anti-Pneumocystis defense

250 [16]. This cell may recognize Pneumocystis and clear it from the lungs via an inflammatory

251 response leading to TNFa, $\mathrm{L} 6, \| \mathrm{L} 1 \beta$ secretion. Also, macrophage could balance

252 inflammatory response via IL10 secretion. Steroids may modify the balance between

253 inflammatory and antifungal function by modifying macrophage response [10].

254 The pathogenicity of Pneumocystis could then be different according to the underlying 255 disease or treatment. Our study brings some arguments to explore the different type of 256 Pneumocystis disease. Thus, response to adjuvant therapy may be variable according to 257 the underlying disease $[17,18]$.

258 Pneumocystis pneumonia in non-AIDS patients remains associated with high mortality, up 259 to $50 \%$, according to the underlying disease [14]. Although this infectious disease was 260 associated with severe hypoxemia, shock remained rare. Consistently, in our study, only $2618 \%$ of patients had shock during the course of Pneumocystis pneumonia. Only Day 30 262 mortality was analyzed to reduce the bias for the mortality related to the underlying 263 disease. However, mortality remained higher in hematological diseases patients than in 264 patients with solid organ transplant or immunosuppressive treatment. The severity of the 265 underlying disease and the possibility of treatment after Pneumocystis pneumonia 266 recovery may influence mortality and clinical decisions. 
267 Our study had several limitations. First, this was a retrospective study, with missed data.

268 However, we used a multiple imputation approach for the analysis and performed a 269 sensitivity analysis on complete cases which did not modify results on factors associated

270 with Day 30 mortality.

271 Second, data were recorded more than 10 years ago and medical care would be modified

272 within this period. However, the primary objective of the study was to discriminate PCP

273 presentation between several underlying diseases. Although, treatments and ICU 274 procedures have been improving within the last 10 years which could have modified 275 mortality, PCP presentation at admission may remained stable according to the underlying 276 immunosuppression.

277 We also had no information about the functional status of each patient and their nutritional 278 status, or comorbidities, which are also known factors associated with the outcome of 279 these patients in the ICU and in the hospital [19]. Comorbidity scores, body mass index, 280 and functional status were probably not the same in different patient groups, all of which 281 could influence mortality.

282 Moreover we had no information about the decrease of dose or the suspension of 283 immunosuppressive treatments in each group, which may also had an impact on the final 284 outcome.

285 Finally, we separated patients in six groups according to the underlying disease, resulting 286 in a limited number of patients in each group.

\section{Conclusion}

288 To conclude, our study shows different presentations and prognoses of Pneumocystis 289 pneumonia according to the underlying disease. These differences may be explained with 290 the different types of alterations of the immune system. All those data should be confirmed 291 with further study. Our study added hypothesis concerning presentation and response to 
292 treatment according the underlying diseases. For example, analyzing response to 293 adjunctive steroids for non-AIDS patients with PCP may include underlying disease in the 294 further study. Likewise, mortality is associated with the severity of the patients at the time 295 of diagnosis, determined by the presence of shock and higher need of oxygen. 296 
297 Ethical approval: The appropriate ethics committee approved the first 298 study

299 Consent to participate : non applicable

300 Consent to publish : non applicable

301 Informed consent: It was not required because of observationnal study

302 Authors contributions :

$303 \mathrm{~GB}, \mathrm{LB}, \mathrm{EA}, \mathrm{VL}$ design the study, performed analysis and wrote the manuscript

304 AR, SV, FRG. SH, DM, AD, SLG. FD, ML, DT, CP, APB, JB, AB, XI, IDJ, DM, DP, CH, EM, 305 included patients, reviewed and approved the manuscript

307 Funding: The initial cohort was supported by a grant from the French ministry of health.

308 Competing Interest: Antoine Roux, MD,; Sandrine Valade, MD; Florence Gangneux309 Robert, PharmD, PhD; Samia Hamane, MD; Daniele Maubon, MD, PhD; Anne 310 Debourgogne, PhD, MPH; Solène Le Gal, DVM, PhD; Frederic Dalle, PharmD, PhD; 311 Marion Leterrier, PharmD; Dominique Toubas, MD, PhD; Christelle Pomares, MD, PhD; 312 Anne Pauline Bellanger, PharmD, PhD; Julie Bonhomme, MD, PhD; Xavier Iriart, PhD; 313 Isabelle Durand-Joly, PhD; Denis Magne, PhD; Denis Pons, Pharmacien Biologiste; and 314 Eric Maury, MD, PhD, have disclosed no relevant financial relationships. Christophe 315 Hennequin, MD, $\mathrm{PhD}$, has disclosed the following relevant financial relationships: served 316 as an advisor or consultant for Gilead Sciences, Inc., Merck Sharp \& Dohme Corp; Pfizer 317 Inc. Elie Azoulay, MD, PhD, has disclosed the following relevant financial relationships: 318 Gilead Sciences, Pfizer, Astellas, Alexion, Fisher-Paykel. Dr Lemiale has disclosed being 319 memeber of a research group which received grant from Pfizer, Fisher-Paykel, gilead, 320 Alexion, Astellas.

322 Availability of data and materials : data are avalaible on reasonnable request. required 323 because of observational study. 


\section{References}

326

327

328

329

330

331

332

333

334

335

336

337

338

339

340

341

342

343

344

345

346

347

348

349

350

351

352

353

354

355

356

357

358

359

360

361

362

363

364

365

366

367

368

369

370

371

372

373

[1] Bollée G, Sarfati C, Thiéry G, Bergeron A, de Miranda S, Menotti J, et al. Clinical picture of Pneumocystis jiroveci pneumonia in cancer patients. Chest 2007;132:1305-10.

[2] Gonzalez Santiago TM, Wetter DA, Kalaaji AN, Limper AH, Lehman JS. Pneumocystis jiroveci pneumonia in patients treated with systemic immunosuppressive agents for dermatologic conditions: a systematic review with recommendations for prophylaxis. Int J Dermatol 2016;55:823-30.

[3] Matsumoto T, Fujita M, Hirano R, Sasaki T, Watanabe K. Risk factors for pneumocystis pneumonia onset in HIV-negative patients treated with high-dose systemic corticosteroids. Infect Dis (Lond) 2019;51:305-7.

[4] Park SY, Jung JH, Kwon H, Shin S, Kim YH, Chong Y, et al. Epidemiology and risk factors associated with Pneumocystis jirovecii pneumonia in kidney transplant recipients after 6- month trimethoprim- sulfamethoxazole prophylaxis: A case- control study. Transpl Infect Dis 2020;22.

[5] Watanabe H, Kitahara Y, Murakami Y, Nihashi F, Matsushima S, Eifuku T, et al. Pneumocystis jirovecii Pneumonia in a Patient with Breast Cancer Receiving Neoadjuvant Dose-dense Chemotherapy. Intern Med 2020;59:987-90.

[6] Roux A, Canet E, Valade S, Gangneux-Robert F, Hamane S, Lafabrie A, et al. Pneumocystis jirovecii Pneumonia in Patients with or without AIDS, France. Emerg Infect Dis 2014;20:1490-7.

[7] Monnet X, Vidal-Petiot E, Osman D, Hamzaoui O, Durrbach A, Goujard C, et al. Critical care management and outcome of severe Pneumocystis pneumonia in patients with and without HIV infection. Crit Care 2008;12:R28.

[8] Festic E, Gajic O, Limper AH, Aksamit TR. Acute respiratory failure due to pneumocystis pneumonia in patients without human immunodeficiency virus infection: outcome and associated features. Chest 2005;128:573-9.

[9] Gassner FJ, Weiss L, Geisberger R, Hofbauer JP, Egle A, Hartmann TN, et al. Fludarabine modulates composition and function of the $\mathrm{T}$ cell pool in patients with chronic lymphocytic leukaemia. Cancer Immunol Immunother 2011;60:75-85.

[10] Thomas CF, Limper AH. Current insights into the biology and pathogenesis of Pneumocystis pneumonia. Nat Rev Microbiol 2007;5:298-308.

[11] Werbel WA, Ison MG, Angarone MP, Yang A, Stosor V. Lymphopenia is associated with late onset Pneumocystis jirovecii pneumonia in solid organ transplantation. Transpl Infect Dis 2018;20:e12876.

[12] Pagano L, Fianchi L, Leone G. Fungal Pneumonia Due to Molds in Patients with Hematological Malignancies. Journal of Chemotherapy 2006;18:339-52.

[13] Tasaka S, Tokuda H. Pneumocystis jirovecii pneumonia in non-HIV-infected patients in the era of novel immunosuppressive therapies. Journal of Infection and Chemotherapy 2012;18:793-806.

[14] Gaborit BJ, Tessoulin B, Lavergne R-A, Morio F, Sagan C, Canet E, et al. Outcome and prognostic factors of Pneumocystis jirovecii pneumonia in immunocompromised adults: a prospective observational study. Ann Intensive Care 2019;9:131.

[15] Thomas CF, Limper AH. Pneumocystis pneumonia. N Engl J Med 2004;350:2487-98.

[16] Nandakumar V, Hebrink D, Jenson P, Kottom T, Limper AH. Differential Macrophage Polarization from Pneumocystis in Immunocompetent and Immunosuppressed Hosts: Potential Adjunctive Therapy during Pneumonia. Infect Immun 2017;85.

[17] Moon SM, Kim T, Sung H, Kim M-N, Kim S-H, Choi S-H, et al. Outcomes of moderate-to-severe Pneumocystis pneumonia treated with adjunctive steroid in nonHIV-infected patients. Antimicrob Agents Chemother 2011;55:4613-8. 
[18] Wieruszewski PM, Barreto JN, Frazee E, Daniels CE, Tosh PK, Dierkhising RA, et al. Early Corticosteroids for Pneumocystis Pneumonia in Adults Without HIV Are Not Associated With Better Outcome. Chest 2018;154:636-44.

[19] Borcoman E, Dupont A, Mariotte E, Doucet L, Joseph A, Chermak A, et al. One-year survival in patients with solid tumours discharged alive from the intensive care unit after unplanned admission: A retrospective study. J Crit Care 2020;57:36-41.

[20] Fishman JA, Gans H, AST Infectious Diseases Community of Practice. Pneumocystis jiroveci in solid organ transplantation: Guidelines from the American Society of Transplantation Infectious Diseases Community of Practice. Clin Transplant 2019;33:e13587. 
387 Tables and figures legend

388 Table 1: Characteristics at diagnosis according to the underlying disease

390 * Missing values: gender $(n=11)$, age $(n=8)$, prophylaxis $(n=42)$, duration of respiratory 391 symptoms $(n=91)$, temperature $(n=102)$, cough $(n=119)$, dyspnea $(n=113)$, Sa02 $(n=$ 392 184), oxygen flow $(n=144)$, ICU admission $(n=52)$, time from admission to treatment $(n=$ 393 115), and day 30 mortality $(n=41)$

394

395 Table 2: Univariate analysis of risk factors associated with DAY 30 mortality

396 IS: immunosuppressive treatment. CLL: chronic lymphoid leukemia

398 Table 3: Multivariate analysis of factors associated with DAY 30 mortality

Figure 1: Multiple correspondence analysis of clinical symptoms in non-AIDS

401 Pneumocystis patients according to the underlying disease

402 First two components could explain variability in observations up to 22.6 and $25.7 \%$.

403

404

405

406

407

408

409

410

411

412

Figure 2: Multiple correspondence analysis of patients according to the underlying disease. 
Table 1

\begin{tabular}{|c|c|c|c|c|c|c|c|c|}
\hline Variables & $\begin{array}{l}\text { Hematological } \\
\text { malignancy } \\
(n=75)\end{array}$ & $\begin{array}{l}\text { Chronic lymphoid } \\
\text { leukemia } \\
(n=19)\end{array}$ & $\begin{array}{l}\text { Allogeneic stem } \\
\text { cell transplant } \\
\qquad(n=14)\end{array}$ & $\begin{array}{l}\text { Solid tumor } \\
\qquad(n=39)\end{array}$ & $\begin{array}{c}\text { Solid organ } \\
\text { transplant } \\
(n=94)\end{array}$ & $\begin{array}{c}\text { Immunosuppres } \\
\text { sive treatment } \\
(n=57)\end{array}$ & $\begin{array}{c}\text { Other } \\
\text { immunosupre } \\
\text { ssive } \\
\text { condition }\end{array}$ & $\mathrm{p}$ \\
\hline Age (year)* & $61[52-73]$ & $67[62-76]$ & $43[32-57]$ & $59[49-64]$ & $54[44-61]$ & $64\{53-74]$ & $60[43-68]$ & $<0.001$ \\
\hline Male gender* & $47(67)$ & $12(63)$ & $8(62)$ & $21(54)$ & $59(65)$ & $30(55)$ & $16(70)$ & 0.67 \\
\hline $\begin{array}{l}\text { No prophylaxis or } \\
\text { recently withdrawn prophylaxis* }\end{array}$ & $64(85)$ & $15(79)$ & $8(57)$ & $38(97)$ & $76(80)$ & $52(96)$ & $13(100)$ & $<0.001$ \\
\hline Steroids prior to PCP & $26(35)$ & $4(21)$ & $8(57)$ & $17(44)$ & $75(80)$ & $51(89)$ & $2(9)$ & $<0.001$ \\
\hline $\begin{array}{l}\text { Duration of res piratory } \\
\text { symptoms (days)* }\end{array}$ & $5[0-15]$ & $15[10-26]$ & $26[12-30]$ & $4[0-7]$ & $7[0-15]$ & $4[0-12]$ & $6[4-14]$ & 0.004 \\
\hline Dyspnea* & $37(79)$ & $11(85)$ & $8(89)$ & $13(54)$ & $43(68)$ & $30(73)$ & $9(82)$ & 0.22 \\
\hline Cough* & $29(62)$ & $12(86)$ & $5(71)$ & $7(30)$ & $34(58)$ & $18(44)$ & $4(36)$ & 0.013 \\
\hline $\mathrm{T}^{\circ}>38^{\circ} \mathrm{C}^{*}$ & $48(91)$ & $13(93)$ & $8(100)$ & $15(65)$ & $53(83)$ & $35(78)$ & $9(75)$ & 0.085 \\
\hline Sa $\mathrm{O} 2$ at admission (\%)* & 90 [87-94] & 93 [87-96] & 83 [74-96] & $90[86-96]$ & $92[90-96]$ & 95 [89-98] & 72 [64-85] & 0.13 \\
\hline $\begin{array}{l}\text { Oxygen flow at admission } \\
(\mathrm{L} / \mathrm{min})^{*}\end{array}$ & $0[0-4]$ & $0[0-1]$ & $0[0-6]$ & $2[0-14]$ & $0[0-2]$ & $6[0-14]$ & $0[0-4]$ & 0.069 \\
\hline ICU admission* & $26(42)$ & $4(25)$ & $9(69)$ & $18(53)$ & $37(47)$ & $33(65)$ & $7(47)$ & 0.055 \\
\hline $\begin{array}{l}\text { Time from hospital admission to } \\
\text { treatment (days)* }\end{array}$ & $2[1-6]$ & $2[0-3]$ & $0[0-1]$ & $2[1-8]$ & $2[1-6]$ & $2[0-4]$ & $7(1-10)$ & 0.081 \\
\hline D30 Mortality* & $15(22)$ & $3(17)$ & $6(50)$ & $14(40)$ & $6(8)$ & $17(33)$ & $3(17)$ & $<0.001$ \\
\hline
\end{tabular}




\begin{tabular}{l|c|c}
\hline \hline Variables & OR [Cl95\%] & $p$ \\
\hline Age (> or <65 years) & $2.37[1.35-4.18]$ & 0.003 \\
Gender (female) & $0.92[0.52-1.64]$ & 0.77 \\
Underlying conditions & & \\
$\quad$ Solid tumor and IS* treatment & 1 & 0.0002 \\
$\quad$ Solid organ transplantation & $0.18[0.07-0.44]$ & 0.083 \\
$\quad$ Hematological malignancy or chronic lymphoid leukemia & $0.56[0.29-1.08]$ & 0.13 \\
$\quad$ Allogeneic stem cell transplantation & $2.45[0.77-7.83]$ & \\
Prophylaxis & & 0.009 \\
$\quad$ None & 1 & \\
Continuous & $0.25[0.09-0.70]$ & \\
Duration of respiratory symptoms & & 0.17 \\
$\quad$ > days & 1 & 0.58 \\
$7-21$ days & $0.58[0.27-1.25]$ & 0.40 \\
$>21$ days & $0.74[0.26-2.13]$ & 0.083 \\
T>38 ${ }^{\circ} \mathrm{C}$ & $1.47[0.59-3.64]$ & 0.49 \\
Cough & $0.54[0.27-1.09]$ & 0.029 \\
Dyspnea & $1.32[0.59-2.93]$ & $<0.0001$ \\
SaO2 at diagnosis & $0.96[0.93-1.00]$ & 0.0005 \\
Oxygen flow at diagnostic & $1.15[1.08-1.22]$ & 0.075 \\
Shock at admission & $4.95[2.03-12.1]$ & 0.14 \\
Hospital acquired or coinfection & $1.72[0.95-3.13]$ & \\
Adjuvant Steroid therapy & $1.58[0.86-2.93]$ & \\
\hline \hline
\end{tabular}


Table 3

\begin{tabular}{l|l|l}
\hline \hline Variables & OR [CI95\%] & $\mathrm{p}$ \\
\hline Underlying conditions & & \\
$\quad$ Solid tumor and Is treatment & 1 & \\
Solid organ transplantation & $0.19[0.07-0.53]$ & 0.001 \\
Hematological malignancy or chronic lymphoid leukemia & $0.75[0.34-1.63]$ & 0.47 \\
Allogeneic stem cell transplantation & $3.60[0.93-13.9]$ & 0.06 \\
Oxygen flow at diagnostic & $1.16[1.08-1.24]$ & $<0.0001$ \\
Shock at admission & $7.67[2.63-22.37]$ & 0.0002 \\
\hline \hline
\end{tabular}


Dimensions 1 and 2 factor map

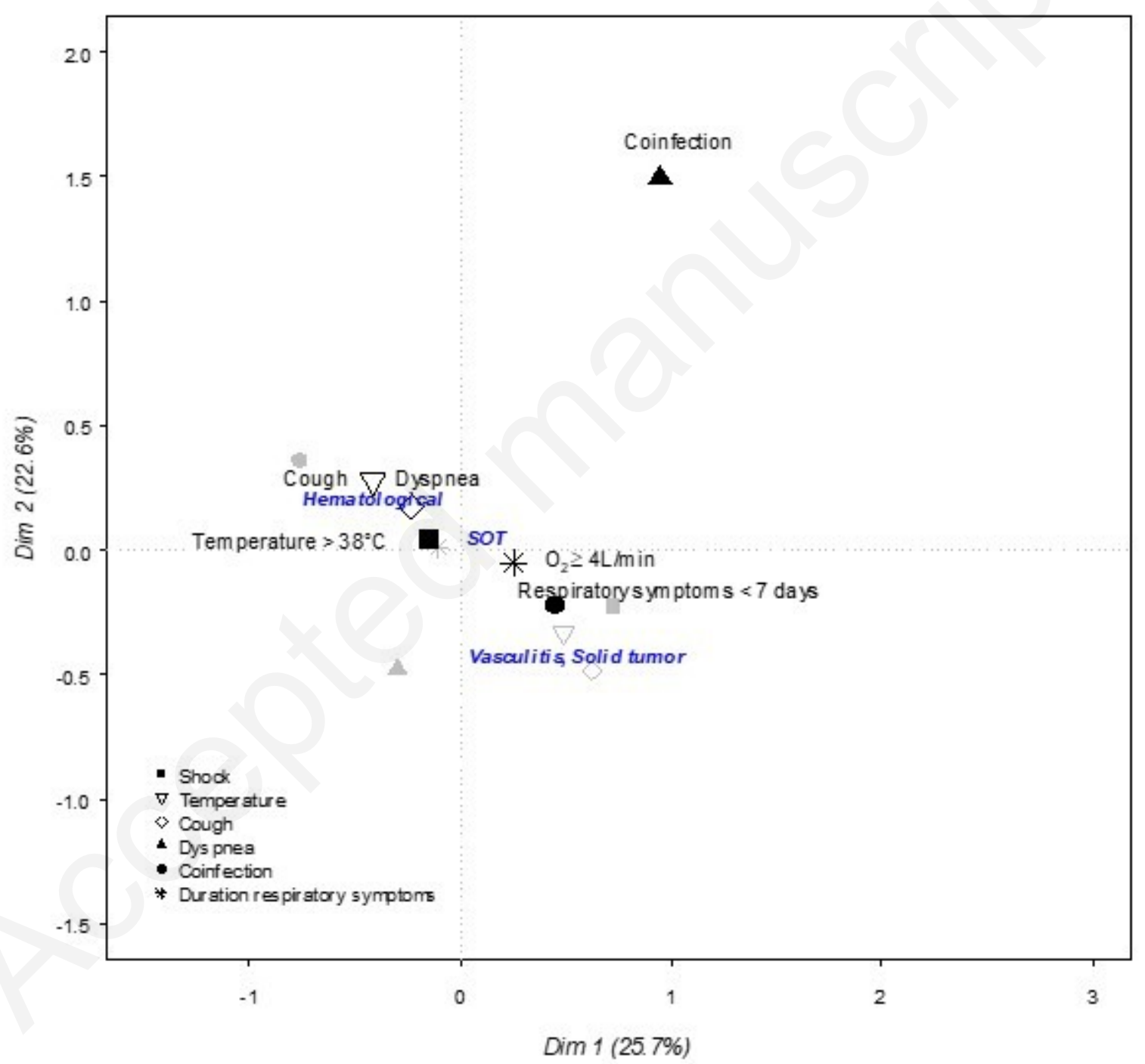


Dimens ions 1 and 2 factor map

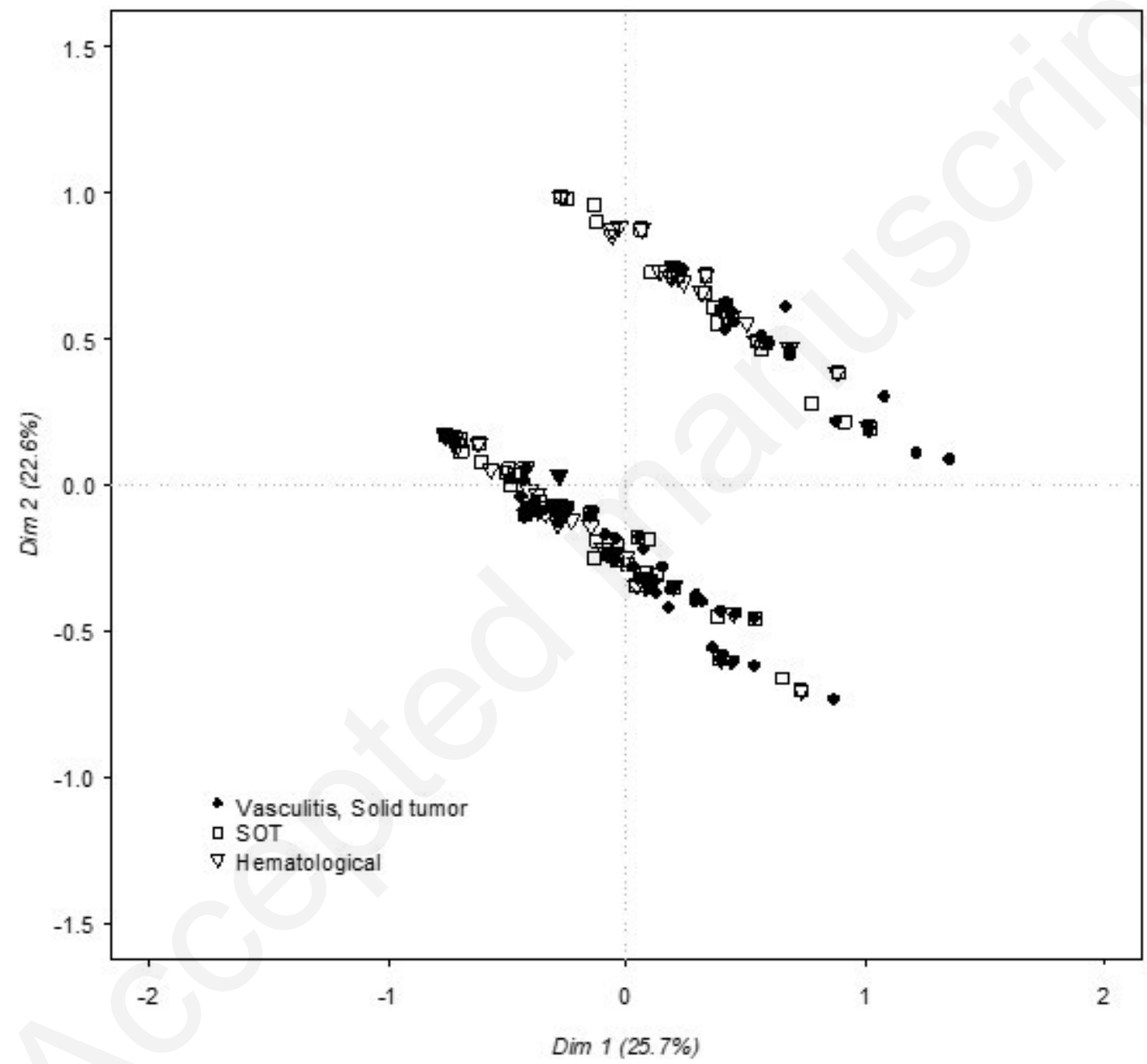

